\title{
JOHN DEWEY Y LA TRAGEDIA DE LOS COMUNES
}

\section{JOHN DEWEY AND THE TRAGEDY OF THE COMMONS}

\author{
José Miguel Esteban Cloquell* \\ Universidad Autónoma de Querétaro
}

\begin{abstract}
Resumen: Este artículo ${ }^{1}$ persigue mostrar cómo los conceptos y las prácticas de participación democrática contenidos en la obra de Dewey posibilitan comunidades de investigación que enfrentan cooperativamente la tragedia de los comunes y otros dilemas sociales que la crisis socio-ecológica plantea a las sociedades contemporáneas. Tras analizar el modelo simplificado de racionalidad económica que subyace en la formulación que Hardin presenta en La tragedia de los comunes (1968), se explora la presencia de esos conceptos en la noción alternativa de racionalidad bosquejada por Elinor Ostrom para hacer frente al desafío de Hardin. Por último, se analiza la Investigación Acción (Action Research) como una heurística contemporánea que responde a ese desafío recurriendo explícitamente a la democracia participativa de John Dewey.
\end{abstract}

Palabras Clave: tragedia de los comunes, racionalidad, democracia participativa, investigación acción

Авsтract: This paper seeks to show how Dewey's concepts and practices of democratic participation make communities of inquiry which cooperate to face the tragedy of the commons and other social dilemmas presented by the environmental crisis possible.

\footnotetext{
*jmesteban.mikele@gmail.com. Universidad Autónoma de Querétaro, Cerro de las Campanas, s/n Col. Las Campanas, Santiago de Querétaro, Querétaro C.P. 7601016 de Septiembre, s/n, Col Centro Histórico México

${ }^{1}$ El presente trabajo presenta con ligeras modificaciones la videoconferencia "Democracia participativa en tiempos de crisis ecológica y social", impartida en el Symposium Rethinking Dewey, celebrado en Alcalá de Henares entre el 18 y el 20 de octubre de 2012. Agradezco a dos revisores anónimos de Endoxa las sugerencias para su publicación.
} 
After analyzing the simplified model of economic rationality underlying Hardin's challenge in The tragedy of the commons (1968), the paper explores the presence of these Deweyan concepts in the alternative notion of cooperative rationality sketched out by Elinor Ostrom to respond to this challenge. Finally, Action Research is introduced as heuristics which explicitly responds to this challenge by means of Dewey's participatory democracy.

KEYWORDs: tragedy of the commons, rationality, participatory democracy, action research

\section{Introducción}

Las tesis de Dewey sobre democracia participativa han recibido críticas por parte de algunos autores que se declaran pragmatistas. En Forjar nuestro pais, (1998) Richard Rorty unía la idea deweyana de democracia participativa a una nueva izquierda cultural que jamás habría abandonado su pretenciosidad teórica, ni habría logrado salir de los recintos universitarios:

La izquierda cultural ha contribuido a la formación de una conciencia políticamente superflua no sólo por considerar al poder como una presencia invisible, ubicua y malévola, sino también por adoptar ideales que nadie es capaz de imaginar cómo se realizarán. Entre esos ideales está la democracia participativa [...] pero nadie sabe de qué se trata. En los años sesenta no se planteó cómo los diversos grupos de cooperativistas alcanzarían consenso sobre cuándo hay que remodelar una fábrica, en vez de construir una nueva, o qué precios hay que pagar por las materias primas y cosas de este estilo. [...] hoy día la izquierda cultural sigue tomándose a la ligera estas cuestiones. Y lo hace a causa de su propensión a hablar del "sistema" en vez de discutir sobre prácticas sociales concretas y cambios concretos de esas prácticas. La retórica de esta izquierda sigue siendo revolucionaria, y no reformista y pragmática [...] el público que debe salir ganando si la izquierda sale de la academia y entra en la escena pública, desea razonablemente que se le hable más claro y en concreto [...] desea saber cómo se supone que va a funcionar la democracia participativa [...] cómo las asambleas participativas aprenderían las mismas técnicas que ahora poseen sólo los tecnócratas. Incluso alguien como yo mismo, cuya admiración por John Dewey no tiene límite, no puede tomarse seriamente su defensa de la democracia participativa en 
contra de Walter Lippmann, cuando éste insistió en la necesidad de que existieran expertos. (1998: 92-93).

En este trabajo trataré de responder estas objeciones de Rorty a la democracia participativa de Dewey mostrando su vigencia para abordar algunos de los problemas ecológicos y sociales que hoy aquejan a las sociedades contemporáneas. A mi modo de ver, Rorty menosprecia, si no es que simplemente ignora, los factores cognitivos presentes en lo que algunos intérpretes de Dewey como Campbell y Bohman han denominado la democracia como investigación cooperativa. Es cierto que, como dice Larry Hickman, hay áreas de la experiencia socialmente compartida donde el conocimiento nada tiene que hacer. Pero hay muchas otras donde sí. No puedo estar más de acuerdo con Hickman cuando afirma que «los públicos tienden a constituirse en respuesta al reconocimiento público de los problemas que comparten» (Hickman, 2007: 46). Adoptando este enfoque, una comunidad democrática de investigación cooperativa se constituye en la práctica en torno a un problema o a un conjunto de problemas que, de un modo u otro, afectan a los miembros que la conforman. Lejos de excluir el disenso y la deliberación, se necesita conocimiento, investigación y juicios prácticos para la elección entre los cursos alternativos de acción que pueden tomarse para solucionar ese problema o ese conjunto de problemas.

En este trabajo recurriré a algunos casos exitosos de democracia como investigación cooperativa en la resolución de crisis y problemas concretos en torno a bienes comunes sociales y ecológicos, casos que corroboran la viabilidad de una idea operativa de participación inspirada en los distintos conceptos, valores y prácticas presentes en la obra de John Dewey. Para introducir mi tratamiento de estos casos de investigación cooperativa, permítanme citar tres textos que permiten sumarnos a Larry Hickman también en su defensa de Dewey como educador y pensador ambiental.

El primer texto pertenece a Naturaleza Humana y Conducta (1922):

La cuestión moral atañe al futuro [...] el problema moral es el problema de modificar los factores que hoy influyen en los resultados futuros [...] Lo mejor que podemos hacer para la posteridad es trasmitirle, conservando sin mermas e incrementando su significado, el ambiente que hace posible mantener los hábitos de una vida digna y prolija. Nuestros hábitos individuales 
son eslabones que forman la interminable cadena de la humanidad. Su valor depende del ambiente que hemos heredado de nuestros antecesores y se incrementa a medida que anticipamos las consecuencias de nuestras acciones sobre el mundo en que vivirán nuestros sucesores [...] los hábitos perduran porque incorporan en sí mismos las condiciones objetivas del ambiente. (Dewey, 1922: 18 )

El segundo es un fragmento de un artículo publicado en 1937, titulado Libertad:

[la libertad económica individual] también ha alentado un desaforado espíritu de especulación que supone un considerable lastre para las generaciones presentes y futuras. Ha impulsado una explotación temeraria y extravagante de los recursos naturales, como si fueran literalmente inagotables $[. .$.$] conservar el suelo, restaurar, hacer nuevamente fértiles tierras ya$ exhaustas, combatir los vertidos y la erosión, que han convertido grandes zonas de nuestro patrimonio natural en algo parecido a un desierto [...] ése es el precio que hemos de pagar por habernos embarcado en una orgía de supuesta libertad económica. Sin suficientes recursos naturales, no es posible una libertad que sea igual para todos. Sólo disfrutarán de libertad quienes ya los posean. Para lograr una genuina igualdad de oportunidades, no basta con retocar nuestras políticas tradicionales de derroche y destrucción. Es necesario revertirlas. (Dewey, 1937: 251).

En el primer texto, mucho antes que Hans Jonas, Dewey establece que la acción moral y la reflexión ética tienen necesariamente que ver con las consecuencias futuras de nuestras prácticas, estableciendo de manera muy general nuestra mayor obligación con las generaciones venideras, a saber, transmitirles un ambiente social y ecológicamente valioso, mejorando los hábitos y prácticas que recibimos de nuestros predecesores y desarrollando mejores métodos para anticipar las consecuencias de nuestras prácticas sobre el ambiente que esas generaciones necesariamente van a heredar. Si los hábitos perduran porque llevan en sí mismos las condiciones objetivas del ambiente, bien podríamos decir que transmitir una cultura y transmitir un medio ambiente son dos descripciones alternativas de un mismo proceso. 
En el segundo texto, Dewey cuestiona la calidad de los procesos de transmisión cultural existentes (entones y ahora), llamando la atención sobre algunas de las consecuencias (ecológicas y sociales) de las prácticas económicas individualistas sobre un medio ambiente futuro e incierto, pero que ya podía anticiparse en los años treinta y que, pese a las advertencias de Dewey y de otros muchos, no ha hecho más que empeorar. Por apuntar solo un dato: según los ecólogos (Marten, 2001), han bastado sólo 12 de las 60.000 generaciones de humanos que han vivido en el planeta para llegar a la actual tasa de extinción de especies, entre 1,000 y 10,000 veces más que la tasa media de extinción durante los 60 millones de años anteriores a la Revolución Industrial.

Considerando conjuntamente ambos textos, podríamos decir que, según Dewey, lo primero que las generaciones presentes tendríamos que hacer para mejorar la transmisión cultural de un ambiente valioso a las generaciones futuras es investigar seriamente las consecuencias ecológicas de nuestros hábitos y nuestras prácticas, la huella ecológica de nuestra actual forma de vida. Conocidas estas consecuencias, un demócrata deweyano tendrá que asumir la responsabilidad de participar como pueda en la transformación de nuestras democracias de consumo, esto es, de nuestras prácticas masivas de extracción, producción, consumo y desecho de recursos naturales, ya que, según Dewey, concebida como igualdad de oportunidades, no hay democracia genuina sin esa transformación, sin un uso sustentable de estos recursos.

Con esto llegamos al siguiente texto de Dewey, perteneciente a Filosofía $y$ democracia (1919):

Si nuestro objetivo es construir instituciones democráticas, ¿̨cómo hemos de construir e interpretar el ambiente natural y nuestra historia natural para que nuestros esfuerzos tengan un respaldo intelectual, para estar razonablemente convencidos de que nuestro empeño no contradice lo que la ciencia nos autoriza a afirmar sobre la estructura del mundo? (Dewey, 1919: 48).

Creo que este texto habría sublevado a Rorty aún más que el que recordaba en su cita. Pero no es necesario ver aquí una búsqueda filosófica de la democracia como el espejo de la naturaleza. Cabría interpretar que Dewey, aunque con una retórica de otro siglo, podría estar preguntándose por algo parecido a lo que hoy llamaríamos las condiciones ecológicas para una forma de vida democrática. Y 
muy probablemente muchos recordarán en este punto la tesis de Heidegger, quien vaticinaba que la democracia y el humanismo eran la peor manera de habérnoslas con las consecuencias planetarias de la tecnología (Heidegger, 1966), o la demanda de Heilbroner (1974), quien exigía la mano de hierro de una dictadura militar para resolver los problemas ecológicos del último tercio del siglo XX.

Para Dewey, nuestras prácticas no pueden ser social e intergeneracionalmente justas si no son ecológicamente válidas. Pero otros han interpretado la historia natural de la humanidad de tal manera que niegan que conservación ecológica y justicia social hayan sido y puedan ser siquiera compatibles, tanto a corto como a largo plazo. ¿Cómo responder a este desafío socioecológico desde una democracia entendida como investigación cooperativa?

\section{EI desafío de Hardin}

No han faltado ecologistas y economistas conservadores que han defendido abiertamente políticas socialmente injustas para evitar la ruina ecológica y económica de todos. Tal defensa depende muchas veces de argumentaciones aprioristicas o de experimentos mentales que resultan ajenos a la conducta real de las personas. Algunos autores de la teoría contemporánea de la elección racional, por ejemplo, postulan una misma estructura en muchos de los problemas asociados a la crisis económica y al empobrecimiento de los servicios ambientales. Se trata de la estructura de los denominados dilemas sociales (Ostrom, 1990). Basándose en modelos económicos muy idealizados, algunos autores de esta corriente han empleado los dilemas sociales para predecir precisamente las trágicas consecuencias de las políticas sociales que privilegian la justicia distributiva sobre la eficiencia ecológica y económica (Hardin, 1968). La teoría económica de la elección racional ha encontrado en la tragedia de los comunes una forma engańosamente fácil para explicar cómo las elecciones que las personas toman individual y racionalmente pueden conducir a la irracionalidad colectiva y al desastre.

En La tragedia de los comunes (1968) Garret Hardin nos habla de un pastizal (un bien común) sobre el que todos los individuos y las familias de una comunidad tienen igual derecho a poner libremente a pastar su ganado. Hardin plantea que, ante la posibilidad de aumentar o no una cabeza de ganado al rebaño que 
pasta en esa zona común, la única elección racional que cada pastor puede tomar individualmente es siempre ańadir un animal más. La razón que aduce es que el beneficio que le reporta al pastor la venta de los productos de esa cabeza adicional (1) será íntegramente para él, mientras que el coste que produce el sobrepastoreo del pastizal será compartido por los $n$ pastores de la comunidad. Siendo para él el beneficio (1) $n$ veces el coste, «el pastor racional concluye que la única decisión sensata para él es ańadir otro animal a su rebaño» (Hardin, 1968: 1244). Pero, lamentablemente, ésta es la conclusión a la que llegan todos y cada uno de los pastores racionales (sic) que comparten el pastizal. De ahí que el pastizal, el bien común de la comunidad de pastores, finalmente desaparezca, como consecuencia de elecciones racionales económicamente impecables en términos individuales, pero colectivamente desastrosas. En realidad, lo que Hardin había elaborado no era más que un experimento mental, en el que cada agente individual es prisionero de una racionalidad que lo impulsa a incrementar infinitamente su beneficio explotando un bien común que es ecológicamente finito (Hardin, 1968: 1244).

Con ello Hardin logra evocar la imagen trágica de las crisis ecológicas y económicas como una amalgama de situaciones desesperadas en las que, lo quieran o no, los individuos se ven atrapados mientras asisten indefensos a un proceso inexorable de destrucción de sus bienes comunes. Cabe destacar que, como en el dilema del prisionero, en el experimento mental de Hardin los pastores racionales ni siquiera se comunican entre sí. Resulta llamativo que la racionalidad de la teoría de la elección racional sea una racionalidad tan trágica como silente.

Muchos científicos ambientales y sociales contemporáneos de Hardin generalizaron como conclusión de La Tragedia de los Comunes que las comunidades locales (la gente sencilla, los pueblos) no saben gobernarse a sí mismas y que la autogestión conduce al colapso ecológico. Hardin y los suyos planteaban que ante la tragedia de los comunes sólo existían dos alternativas. $\mathrm{O}$ bien se privatizaba el bien común y se insertaba en un sistema de precios, con lo que supuestamente cada propietario del bien privatizado cuidaría de su propio recurso (siempre que su tasa de descuento no fuese demasiado alta), o bien se sometía el bien común al control de una fuerte autoridad externa y a procesos exógenos, ajenos a la propia comunidad de afectados. Aunque de pasada, Hardin admite que esta disyuntiva se produce dado el legítimo deseo humano de maximizar beneficios, esto es, bajo la creencia de que la naturaleza racional humana es exclusivamente económica o maximizadora, y que, por lo tanto, ese deseo está perfectamente legitimado, independientemente de sus consecuencias ecológicas y sociales. Hardin prefiere considerar a priori legítimo el 
deseo individual de maximizar beneficios ocurra lo que ocurra y deslegitimar la estructura comunitaria de los bienes y la justicia distributiva. El propio Dewey habría visto en la defensa a ultranza de esa legitimidad una «identificación del individualismo económico con la esencia misma de la acción libre, que tanto daño ha hecho y aún puede hacer a la democracia» (Dewey, 1941: 277).

Es esta concepción estrecha de la racionalidad humana la que permite a Hardin predecir la tragedia de los comunes, sus fatales conclusiones y sus remedios expeditivos. Pero no es difícil ver que Hardin pudo extraer una conclusión absolutamente distinta, simplemente con atender a situaciones empíricas en las que numerosas comunidades han evitado el agotamiento de los recursos comunes. Entre otras razones, Elinor Ostrom recibió el premio Nobel de economía precisamente por haber abierto esa línea empírica de investigación sobre el gobierno de los bienes comunes. De haber seguido esa línea, Hardin podría haber concluido que la racionalidad instrumental ortodoxa o completa -entendida como maximización de las relaciones de eficiencia entre medios y fines que reflejan intereses y preferencias subjetivas- conduce inexorablemente al agotamiento de los recursos comunes. Pero el que la maximización de beneficios sea la única elección racional que los pastores pueden tomar es un supuesto a priori. Resulta crucial insistir sobre este hecho: ante el resultado de TC, Hardin siempre pudo poner en cuestión la suficiencia y la completitud de la teoría de la racionalidad económica instrumental en la conducta humana.

\section{La respuesta deweyana de Ostrom}

Como ya se ha dicho, los trabajos de Elinor Ostrom desafían los supuestos y las conclusiones de Hardin. Ostrom equipara la Tragedia de los Comunes con otros dilemas sociales con respecto al bien común, como el dilema del prisionero, y en particular, con el dilema del gorrón o free-rider de Mancus Olson. Técnicamente, un bien común es aquel bien al que cada individuo tiene acceso con independencia de que ese individuo haya cooperado o no para su consecución o su conservación. Poco podemos hacer para que el evasor de impuestos, por ejemplo, deje de disfrutar de los beneficios del alumbrado, los jardines o las carreteras públicas. Olson defiende que un individuo que no puede ser excluido de la obtención de un bien una vez que éste se ha producido, contará con muy pocos incentivos para cooperar en la consecución de ese bien común. La estabilidad climática, por ejemplo, es un tipo de servicio ambiental que la atmósfera podrá 
seguir proporcionándonos a todos sin exclusión, siempre y cuando entre todos logremos contener nuestras emisiones de dióxido de carbono. Para los ambientalistas, la manera de hacerlo es cooperar y, en la medida de lo posible, aplicar en nuestras vidas diarias la regla de las tres $R$ (reducir, reutilizar y reciclar). Ante esta posibilidad, el free-rider parece seguir el siguiente razonamiento: Si ya hay masa critica para detener el calentamiento global, puedo ahorrarme el costo de la cooperación; si no la hay, me perjudica cooperar. Tanto si coopero cuando me lo puedo ahorrar, como si coopero cuando los demás no lo hacen, me tomarán por estúpido. Así que mejor no coopero. Pero claro, si todo el mundo se comporta como gorrón o free-rider y se abstiene de cooperar, algo muy parecido al resultado de la Tragedia de los Comunes resulta inevitable. Cito a Ostrom: "Cuando una persona no puede ser excluida de los beneficios que otros procuran, está motivada a no contribuir en el esfuerzo común y a "gorronear" de los esfuerzos de los otros. Si todos los participantes eligieran "gorronear", no se produciría el beneficio común. La tentación de beneficiarse del trabajo ajeno puede dominar el proceso de decisión, y así todos terminarán en el sitio donde nadie quería estar» (Ostrom, 1990: 46).

Podríamos decir que los dilemas sociales plantean un reto fundamental a ciertos aspectos de la confianza en la naturaleza humana que Dewey vinculaba con la democracia, de la confianza en que los seres humanos como individuos puedan cooperar para alcanzar resultados colectivamente racionales e individualmente enriquecedores. Siguiendo nuestra interpretación de la democracia como investigación cooperativa, podríamos decir que los dilemas sociales pueden quebrar la confianza en la democracia como capacidad participativa de los grupos humanos para emprender autónomamente procesos de investigación que resuelvan cooperativamente sus problemas. Y por eso mismo hay que enfrentarlos.

Las investigaciones empíricas de Elinor Ostrom y Gerald Marten sobre los bienes comunes han hecho mucho para que recuperemos la confianza de Dewey en la democracia participativa, al menos en el aspecto cognitivo que seńalaba al comienzo. Pues, según Dewey, la verdadera prueba de una genuina democracia es su carácter experimental y falibilista, esto es, su capacidad para «llevar a cabo una revisión crítica a fondo de todas nuestras prácticas; ésta es también la única manera de descubrir y poner en marcha medidas que corrijan los defectos» (1951: 62). En vez de apelar a experimentos puramente mentales y supuestos a priori como Hardin, Ostrom y Marten han adoptado un procedimiento experimental y empírico característicamente deweyano, por cuanto estudian casos en los que de hecho ha habido participación inteligente para la consecución del bien común, identifican las características o rasgos deseables en esas formas de 
participación realmente existentes y los emplean para revisar otros rasgos ciertamente indeseables y sugerir experimentalmente su reemplazo o su mejora, pero también para desarrollar procedimientos adecuados a nuevas circunstancias y nuevos problemas.

Siguiendo este procedimiento, Ostrom y Marten han acopiado una cantidad significativa de evidencia empírica de casos de éxito en la consecución y la conservación de los bienes comunes, desmintiendo el trágico pronóstico de los dilemas sociales $^{2}$. En la medida en que estas comunidades han emprendido procesos participativos para tomar decisiones y resolver problemas en torno a sus bienes comunes, admiten ser calificadas como comunidades de investigación cooperativa de las que todos podemos aprender.

Tratando de explicar la conservación del bien común en estos casos, Ostrom y Marten han logrado mostrar que tales comunidades de investigación cooperativa no tienen por objetivo la maximización económica ilimitada —lo que invalida el argumento de Hardin con respecto a la legitimidad a priori de la búsqueda irrestricta de beneficios individuales. En su mayoría, las comunidades que investigan cooperativamente para resolver problemas con respecto a sus bienes comunes mantienen criterios de éxito individual más cercanos a la reputación y al reconocimiento comunitario que a la máxima obtención de propiedad privada. No es de extrañar que, teniendo en cuenta la presencia mayoritaria de estas alternativas en el gobierno exitoso de los bienes comunes comunitarias, Amartya Sen llamara «tarados racionales» (Sen, 1977: 336) a los agentes que «identifican la racionalidad con la maximización del propio interés» (Sen, 1989: 8), olvidando en sus acciones toda restricción procedente de su libre compromiso con personas y proyectos. Combinando los análisis de Sen y de Ostrom (2003), podemos

\footnotetext{
${ }^{2}$ Por citar algunas de la lista de Ostrom: las comunidades de pescadores de Alanya, en el este de Turquía, las comunidades de regantes de la huerta de Valencia y los zanjeros de algunas islas filipinas, los pequeńos agricultores del Nepal o los usuarios de agua potable en California. Gerald Marten ha encontrado muchos otros casos de éxito comunitario: la tenencia comunal de los bosques montańosos en Törbel (Suiza), Hirano, Nagaike y Yamanoka (Japón), en Sierra Juárez (Oaxaca) y, también en México, las comunidades de agrosivilcultura en la zona maya del país y, muy particularmente, las cooperativas pesqueras de Bahía de la Esperanza, al norte de este mismo estado de Quintana Roo. Siguiendo investigaciones como las de Ostrom, Gerald Marten ha logrado identificar más de 100 historias de casos de éxito, incluyendo comunidades para el transporte urbano compartido en Oregón, comunidades canadienses de desarrollo eco-turístico y comunidades de vecinos que comparten huertas urbanas en zonas de la ciudad de Nueva York.
} 
resumir este modelo engañosamente predictivo de la racionalidad ortodoxa o «completa» en los siguientes puntos.

(1) Cada agente dispone de un conjunto de preferencias fijo, completo y lógicamente consistente, no contradictorio, que emplea en cualquier situación y para cualquier propósito.

(2) Existe una correspondencia o una correlación perfecta entre estas preferencias y determinadas contrapartidas o recompensas monetarias, de manera que, por ejemplo, todos los agentes preferirán siempre, cualquiera que sea la situación real, recibir dinero a no recibirlo, independientemente del origen de ese dinero y de las consecuencias que ese devengo puedan tener sobre su comunidad y/o sobre su propia reputación.

(3) Cada agente dispone de toda la información y todo el conocimiento posible para realizar un perfecto cálculo analítico de los costos y los beneficios relevantes implicados en cada una de las estrategias o cursos de acción a seguir.

(4) De acuerdo con este cálculo, todo agente maximizará las utilidades o los beneficios subjetivamente esperados sin que su conducta atienda a ninguna restricción normativa, propia o comunitaria.

(5) Cada agente dispone pues de recursos ilimitados de tiempo y capacidades cognitivas ilimitadas para procesar información procedente de su ambiente, pero no dispone de la capacidad de empatía, reflexión moral y compromiso con el resto de los agentes.

Acudiendo a la evidencia empírica, Ostrom demuestra que este modelo simplificado que, supuestamente, predice siempre la tragedia de los comunes, sólo se cumple en situaciones y comunidades con factores internos característicos:

Puede ser que los participantes simplemente carezcan de la capacidad de comunicarse entre sí, que no sepan cómo tenerse confianza y que ignoren que deben compartir un futuro común. También puede pasar que individuos 
con mayor poder que buscan sacar provecho de la situación actual (mientras que otros pierden) pueden bloquear los esfuerzos de los menos fuertes por cambiar las reglas del juego (Ostrom, 2011: 65).

En vez de asumir que los usuarios de un bien común jamás podrán escapar de la trampa en la que su racionalidad les atrapa, la investigación sobre los casos en los que se evita la tragedia de los comunes permite a Ostrom concluir que la capacidad de los individuos para evadirse de varios tipos de dilemas sociales varía empíricamente de situación en situación. Los resultados del análisis de dichas variaciones posibilitan la formulación de algunos preceptos regulativos:

(1) Los individuos tratan generalmente de resolver sus problemas comunes de la manera más efectiva posible, no de obstaculizar todas las iniciativas que entorpezcan la maximización de beneficios individuales.

(2) En lugar de suponer que la mayoría de los individuos son incompetentes, malos e irracionales y que sólo unos pocos son omniscientes (entre ellos el observador o analista económico de la situación) es más razonable suponer que todos tenemos capacidades finitas más o menos similares para comprender la estructura de ambientes complejos e intentar transformar sus condiciones.

(3) En lugar de considerar las decisiones de los individuos en torno a las reglas y los cambios de reglas para resolver problemas como resultado de procesos mecánicos de cálculo, es más razonable concebir esas elecciones como resultado de procesos falibles para sustentar mejores juicios sobre beneficios y costes inciertos.

Las comunidades de investigación cooperativa que Ostrom y Marten examinan parecen ajustarse a estos preceptos al concertar acciones para acoplar sus sistemas sociales y sus sistemas ecológicos en un único sistema que preserva los bienes comunes, al menos hasta donde sabemos. Su investigación ha tenido que atender sin duda a las condiciones fácticas del bien común, para lo cual han contado con su conocimiento local y con la cooperación de investigadores y participantes externos. En realidad, tales comunidades han seguido principios semejantes a los de la Investigación Acción o Action Research, una modalidad de 
investigación social aplicada que defiende explícitamente el uso de los principios de la democracia como investigación cooperativa de John Dewey para enfrentar dilemas sociaoecológicos y que se aleja significativamente del elitismo tecnocrático que Rorty en ocasiones parece defender.

\section{La Investigación Acción}

En la investigación acción, la comunidad de investigación cooperativa está integrada tanto por investigadores científicos o expertos como por miembros pertenecientes a una comunidad o comunidades locales, cuyos integrantes buscan solventar un problema para mejorar una situación local, tal y como afirman Greenwood y Levin (1998). La investigación acción promueve una participación social amplia en los procesos heurísticos para producir acciones que conduzcan a los implicados en el problema a una situación mejor, más justa o satisfactoria. Juntos, los investigadores externos o expertos y los interesados o participantes internos (1) definen los problemas a abordar, (2) generan conocimientos relevantes acerca de estos problemas, (3) aprenden y ejecutan procedimientos de investigación, (4) emprenden acciones e (5) interpretan los resultados de las acciones basándose en lo que han aprendido conjuntamente. La investigación se concibe como un tipo de acción participativa que sale de los cauces habituales de las instituciones científicas, involucrando activamente a las personas en la generación del conocimiento acerca de su propia condición y de cómo ésta puede ser transformada. Según Falls-Borda y Rahman (1991), la investigación de acción requiere un profundo compromiso por parte de los investigadores participantes de desprofesionalizar su conocimiento experto y compartirlo con la gente, reconociendo a las comunidades directamente implicadas el derecho a mantener su propia voz crítica a la hora de determinar la dirección y los objetivos del proceso de investigación, pasando a ser sujetos activos de la investigación y no meros objetos cuya conducta hay que describir para después prescribirla. En este sentido, la investigación de acción democratiza la relación entre los investigadores expertos y las partes locales interesadas.

Los casos de investigación acción exitosa que recogen Peter Reason y Hilary Bradbury en su Handbook of Action Research (2005) son tan numerosos como los de Ostrom y Marten. Muchos de ellos tienen que ver con la democracia como investigación cooperativa para el manejo de recursos naturales y para corregir la distribución asimétrica del riesgo ambiental en distintas zonas geográficas y 
culturales. Como en el caso de Ostrom, Reason y Bradbury también reportan fracasos de los que futuros investigadores de acción pueden aprender.

En este sentido, la investigación acción intenta deliberadamente evitar los supuestos infundados de los modelos teóricos de la elección racional. Pues, volviendo por el momento a Ostrom, los trágicos dictámenes de la teoría de la elección racional acerca de la incapacidad de la gente para resolver sus problemas y atender a su bien común, y hasta la propia formulación de los dilemas sociales deben su posibilidad a lo que Ostrom llama la trampa intelectual en la que caen los modelos elitistas y tecnocráticos de investigación. Ostrom desentraña esta trampa con una perspicacia propia de Foucault o de Hacking:

La trampa intelectual cuando uno se apoya enteramente en modelos del tipo de la Tragedia de los Comunes como base de análisis de políticas es que los académicos suponen que son observadores omniscientes, capaces de abarcar la esencia del funcionamiento de sistemas complejos y dinámicos, y elaboran descripciones estilizadas de algunos aspectos de esos sistemas. Con la falsa confianza que deriva de una falsa omnisciencia, los académicos plantean propuestas a los gobiernos en el marco de sus modelos como poderes omnicompetentes, capaces de rectificar las imperfecciones en todos los campos. En las concepciones contemporáneas del orden social, el gobierno a menudo es considerado como un agente externo cuya conducta es exógena a la situación modelada. Los analistas que adoptan esta posición se ven a sí mismos como analistas de los comportamientos de los individuos privados y luego como asesores de lo que el gobierno debe hacer (Ostrom, 2011: 357).

La investigación acción trata de eludir esta trampa intelectual participando exclusivamente en investigaciones que atiendan demandas sociales hechas desde fuera de las instituciones científicas y gubernamentales. Los expertos o participantes externos deben ser particularmente receptivos con respecto a las situaciones problemáticas a las que afirman estar enfrentándose los participantes internos, quienes en las investigaciones científicas más al uso quedan marginados ya desde las primeras etapas de la definición o la formulación del problema. La comunicación entre participantes internos y participantes externos o expertos debe iniciarse ya desde la misma definición de la situación problemática, pues, en buena lógica deweyana, la formulación del problema implica ya procesos de selección de los hechos del caso que condicionarán decisivamente las características de su particular resolución. Para que la investigación cooperativa pueda transformar la situación problemática, esos procesos comunicativos entre participantes 
externos e internos deben integrarse en las instituciones y los procedimientos comunicativos que los participantes internos hayan decidido libremente adoptar y mejorar.

En los casos ya señalados, Ostrom ha demostrado que las comunidades de investigación cooperativa que han logrado acoplar sistemas sociales y sistemas ecológicos y preservar el bien común, han tenido en alguna medida que cuidar la calidad de los procesos comunicativos que desarrollan en las instituciones que esas mismas comunidades han logrado levantar de forma autónoma. Además de subscribir acuerdos normativos por consenso explícito, Ostrom demuestra que, en tales comunidades, esa calidad depende de contratos implícitos regidos por la confianza, el compromiso, la reciprocidad y el reconocimiento.

Ostrom y otros han emprendido investigaciones multidisciplinares que sitúan el mutuo refuerzo entre la confianza y la reciprocidad en el origen de la cooperación. En The Evolution of Cooperation (1984) Robert Axelrod había probado que la expectativa de reciprocidad y por lo tanto de un futuro compartido estaba presente en los experimentos con grupos que habían establecido relaciones de confianza para evitar el dilema del prisionero. Ostrom da un paso más, demostrando el papel de una comunicación de calidad, sin distorsiones, para la adquisición de confianza, definida como la disposición a asumir cierto riesgo en la acción con respecto a otros sujetos, con la expectativa de que éstos actuarán recíprocamente. Las comunidades de investigación cooperativa destacadas por Ostrom no han abaratado (cheap-talking) el valor de la palabra, con lo que también han logrado fortalecer la credibilidad o la dignidad de confianza entre sus miembros, dando un valor mayor a los compromisos, a la cooperación, y en consecuencia, a sus bienes comunes.

En mi opinión, las descripciones empíricas que hacen Ostrom y Marten de estos procesos comunitarios encarnan hasta cierto punto algunas de las condiciones comunicativas que Dewey y Habermas adscriben a las comunidades genuinamente democráticas. No todas, claro. Ni Ostrom ni Marten describen acciones comunicativas en comunidades celestiales. No son filosóficamente perfectas, ni simétricas. En cualquier caso, y en mi opinión mucho antes que Habermas, Dewey ya había admitió la idealidad de esas condiciones de simetría comunicativa. Sin duda el tratamiento de Habermas es mucho más sistemático y enciclopédico, y también ha sido empleado en propuestas de democracia deliberativa para el manejo sostenible de los recursos naturales, pero al tratamiento de Dewey tampoco le faltan aciertos. Leemos en La opinión pública y sus problemas: 
La democracia, contemplada como una idea, no es una alternativa a otros principios de la vida asociada. Es la idea misma de vida comunitaria. Es un ideal en el único sentido inteligible de la palabra: es decir, la tendencia y el movimiento de algo que existe llevado hasta su límite [...] dado que las cosas no cumplen esta condición sino que en realidad están sometidas a trastornos e interferencias, la democracia no es un hecho ni nunca lo será. Pero en este sentido tampoco existe ni ha existido nada que sea una comunidad en su completa medida, una comunidad no distorsionada por elementos extrańos. Con todo, la idea o el ideal de una comunidad se corresponde con fases reales de la vida asociada cuando se hallan libres de elementos restrictivos y perturbadores, [...] donde quiera que exista una actividad conjunta cuyas consecuencias se juzguen buenas por todas las personas particulares que intervienen en ella, y donde la consecución de ese bien produzca un deseo firme y un esfuerzo decidido por conservarlo justamente como lo que es, como un bien compartido por todos, donde quiera que ocurra esto habrá una comunidad. La clara conciencia de una vida comunitaria con todas sus implicaciones constituye la idea de democracia. Sólo cuando partimos de una comunidad como un hecho, sólo cuando sometemos este hecho a reflexión para esclarecer y mejorar sus elementos constituyentes, sólo entonces podremos alcanzar una idea de democracia que no sea utópica (Dewey, 2004: 138).

\section{Conclusiones}

La democracia como investigación cooperativa implica lo que Dewey denominaba experimentalismo ético y político: «extraer los rasgos deseables de formas de vida en comunidad que realmente existen y emplearlos para criticar los rasgos indeseables y sugerir su mejora» (Dewey, 1998: 78).

Quizá más que la de ningún otro autor, la lectura Dewey nos sigue aconsejando que practiquemos un recorrido naturalista desde el examen de los buenos hábitos de investigación, comunicación y cooperación hasta la conformación autónoma de instituciones democráticas. Para Dewey, la cooperación dentro de una comunidad de investigación depende también del cultivo de las actitudes y hábitos de reflexión, razonamiento, diálogo y juicio que de hecho valoramos en muchas fases de la experiencia comunicativa y comunitariamente provechosa. El carácter ideal de las condiciones de comunicación para la democracia como 
investigación cooperativa pasa a ser para Dewey un simple recordatorio de nuestra falibilidad, de nuestras limitaciones a la hora de cultivar hábitos y actitudes para la buena deliberación.

En este sentido, como nos recuerda Ramón del Castillo (2004), el significado de la democracia es básicamente co-educativo. La calidad de la comunicación en las comunidades de investigación cooperativa también depende de que sus miembros se ilustren entre sí para superar esas limitaciones. Por supuesto que hay factores coercitivos que impiden el libre desarrollo de esa coeducación. Por supuesto que encontraremos nuevas prácticas sesgadas hacia el poder sobre los demás y no hacia el poder para resolver problemas comunes. También encontraremos prácticas de exclusión interna que habrá que procurar eliminar (al menos yo no veo ningún relativismo paralizante ni ninguna contradicción performativa en la práctica de eliminar prácticas). Por supuesto que muchas veces quedamos muy lejos de la adecuada expresión de estas actitudes y hábitos comunicativos, y otras muchas más simplemente fracasamos, como también ha documentado Ostrom. Pero el reconocimiento de nuestra falibilidad no excluye el reconocimiento de casos de participación democrática mejores y peores. Y entre las mejores, faltaría más, es injusto elegir como representativas las comunidades monolíticas e incapaces de disenso y deliberación o las poses elitistas de la intelligentsia que denunciaba Rorty en Forjar nuestro país. Mi tesis es que las comunidades que de hecho han logrado cuidar sus bienes comunes, como las que describen Ostrom y Marten o Reason y Bradbury, son al menos un buen punto de partida para proseguir con la búsqueda deweyana de la democracia participativa.

\section{Agradecimientos}

El autor agradece, como siempre, la ayuda prestada por Ramón del Castillo.

\section{Bibliografía}

Del Castillo, R. (2004). "Erase un vez en América”, introducción a Dewey, J. (2004): La opinión pública y sus problemas, Madrid: Morata. 
Dewey, J., (1898). "Evolution and Ethics", en Boydston, J.A., (1969). The Early Works of John Dewey, 1882-1898, vol. 5, Carbondale and Edwardsville: Southern Illinois University Press.

-(1908). Ethics, en Boydston, J.A., (1978). The Middle Works of John Dewey, 1899-1924, vol. 5, Carbondale and Edwardsville: Southern Illinois University Press.

-(1911). "The Problem of Truth", en Boydston, J.A., (1978). The Middle Works of John Dewey, 1899-1924, vol. 6, Carbondale and Edwardsville: Southern Illinois University Press.

-(1916). Democracy and Education, en Boydston, J.A., (1980): The Middle Works of John Dewey, 1899-1924, vol. 9, Carbondale and Edwardsville: Southern Illinois University Press.

-(1919) "Philosophy and Democracy" en Boydston, J.A. (1982): The Middle Works of John Dewey, 1899-1924, vol. 11, Carbondale and Edwardsville: Southern Illinois University Press.

-(1922). Human Nature and Conduct, en Boydston, J. (1983) The Middle Works of John Dewey, 1899-1924, vol. 14, Carbondale and Edwardsville : Southern Illinois University Press.

-(1927a). The Public and its Problems en Boydston, J.A., (1984): The Later Works of John Dewey, 1925-1952, vol.2, Carbondale and Edwardsville: Southern Illinois University Press.

-(1929). Individualism, Old and New en Boydston, J.A., (1984): The Later Works of John Dewey, 1925-1952, vol.5, Carbondale and Edwardsville: Southern Illinois University Press.

-(1937). "Freedom”, en Boydston, J.A., (1987): The Later Works of John Dewey, 19251952, vol. 11, Carbondale and Edwardsville: Southern Illinois University Press.

-(1951). "Contribution to Democracy in a World of Tensions" Boydston, J.A., (1981): The Later Works of John Dewey, 1925-1952, vol.16, Carbondale and Edwardsville: Southern Illinois University Press.

Falls-Borda, O. y M.A. Rhaman (eds.) (1991). Action and Knowledge: Breaking the Monopoly with Participatory Action Research, New York: Apex Press.

FIORINO; D. (2010). "Citizen Participation and Environmental Risk: A Survey of Institutional Mechanisms" Technology, \& Human Values (15) 2: 226-243

Greenwood, D. y M Levin: (1998). Introduction to Action Research (Thousand Oaks: Sage)

Hardin, G., (1968): “The Tragedy of the Commons”, Science, 162: 1243-48. 
-(1974). Lifeboat Ethics: the Case Against Helping the Poor [en línea]. Dispon. en: http:// www.garretthardinsociety.org/articles/art_lifeboat_ethics_case_against_helping poor.html [2011, 11 de mayo].

-(1977). Ethical Implications of Carrying Capacity [en línea]. Disponible

en: http://www.garretthardinsociety.org/articles/art_ethical_implications. html [2011, 20 de agosto].

-(1986). Cultural Carrying Capacity [en línea]. Disponible en: http://www.

garretthardinsociety.org/articles/art_cultural_carrying_capacity.html

[2011, 6 de mayo].

-(2001). "Carrying Capacity as an Ethical Concept". The Social Contract,

otoño de 2001, 48-57.

Heidegger, M. (1966). "Nur noch ein Gott kann uns retten”, Der Spiegel, 31 V 1976, 193-199.

Heilbroner, R. (1980). An Inquiry Into the Human Prospect, New York: W.W. Norton.

Hickman, L. (2007). Pragmatism as Pos-posmodernism, New York: Fordham University Press.

Malthus, R. (2000). Ensayo sobre población, Madrid: Alianza Editorial.

Marten, G. (2001). Ecología Humana (Earthscan publications) traducción de David Núñez en pdf [en línea] en http://www.gerrymarten.com/ecologia-humana/indice. html [consultado mayo-noviembre 2012]

-(2012) "Ingredients for Success" [en línea] en http://www.ecotippingpoints.org/aboutetps.html\#lessons [consultado mayo-noviembre 2012]

Olson, M. (1965). The Logic of Collective Action (Cambridge, Mass.: Harvard University Press)

Ostrom, E. (2011). El Gobierno de los Bienes Comunes, México: UNAM, Fondo de Cultura Económica.

-(2003). “Toward a Behavioral Theory Linking Trust, Reciprocity and Reputation”, en OSTROM, E. y J. WALKER (2003)

-(2002). Reformulando los bienes comunes, (en línea), disponible en http://ibcperu. org/doc/isis/2807.pdf [consultado el 21 de agosto 2012]

Ostrom E., Burger, J., Field, C.B., Norgaard, R.B. y Policansky, D. (1999). "Revisiting the Commons: Local Lessons, Global Challenges" Science (284), 278282.

Ostrom E., y Walker, J. (2003). Trust and Reciprocity, New York: Russell Hage. 
Posch, P. (1993). “Action Research in Environmental Education” Educational Action Research 1 (3): 447-455.

Reason, P. y H. Bradbury (2005). Handbook of Action Research, London, Sage.

Rockefeller, S.C. (1991). John Dewey: Religious Faith and Democratic Humanism, New York: Columbia University Press.

-(2004). "Interdependence and global ethics", Disponible en http://www.earthcharterinaction.org/invent/images/uploads/INTERDEPENDENCE\%20AND\%20GLOBAL.pdf [8 de junio 2012]

RorTy, R. (1999). Forjar nuestro pais, Barcelona; Paidós.

Enviado: 2/02/2015

Aceptado: 30/07/2016

\section{(c) $(1) \Theta$}

ENDOXA está bajo una licencia de Creative Commons Reconocimiento-NoComercial-SinObraDerivada 4.0 Internacional 